\title{
Special Issue on Bioconversion, Bioaccumulation and Toxicity of Mercury in a Changing World
}

\author{
Claudia Cosio \\ SEBIO UMR-I 02, Université de Reims Champagne Ardenne, 51687 Reims, France; claudia.cosio@univ-reims.fr \\ Received: 7 September 2020; Accepted: 17 September 2020; Published: 19 September 2020 \\ check for \\ updates
}

\section{Mercury in a Changing World}

Mercury $(\mathrm{Hg})$ is recognized as a persistent global chemical contaminant that accumulates in biota, thus being an ecological hazard, as well as a health risk to fish consumers. Human past and current activities play a predominant role in the emission and mobilization of $\mathrm{Hg}$ in the environment. Elemental $\mathrm{Hg}(\mathrm{Hg} 0)$ and inorganic $\mathrm{Hg}(\mathrm{IHg})$ emitted in the environment are constantly cycled and recycled through $\mathrm{Hg}$ biogeochemical cycle, among which bioconversion by microorganisms into mono-methyl-Hg (MMHg), bioaccumulation ( $\mathrm{MMHg}$ and $\mathrm{IHg}$ ) and biomagnification (MMHg) in food webs is a critical aspect for $\mathrm{Hg}$ toxicity to biota, as well as for humans. Despite decades of research, global $\mathrm{Hg}$ pollution requires a deeper understanding of specific toxicity mechanisms for $\mathrm{Hg}$ compounds and of the mechanisms underlying its transport and accumulation in biota. Indeed, the entrance of $\mathrm{Hg}$ into food webs is not fully understood.

In light of the above, this Special Issue was introduced to collect the latest research on relevant topics, and more importantly to address present challenging issues with the cycling of $\mathrm{Hg}$ in complex systems. The accepted papers addressed various topics, mainly on bioaccumulation, food web transfer, effect and development of new methods in these contexts.

\section{Uptake in Low Trophic Levels}

MMHg has been repeatedly observed to biomagnify through food webs. Hg concentrations at the base of the food web seem to be the main factor controlling Hg transfer in food webs, rather than contrasted biomagnification rates. Risk reduction in top predators being poisoned via ingestion of contaminated preys appears central for $\mathrm{Hg}$ risk management. Three papers concerned uptake of $\mathrm{IHg}$ and MMHg in biota [1-3].

The paper, authored by Vignati et al. (2020), tested the use of standardized laboratory tests to infer $\mathrm{Hg}$ bioaccumulation in indigenous benthic organisms of Lake Maggiore (Italy) [1]. Collecting an adequate amount of biomass to asses $\mathrm{Hg}$ accumulation in resident freshwater benthic invertebrates is a challenge, and site intercomparison may be limited by seasonality, as well as by the availability of species at all monitoring points. Laboratory-reared organisms are attractive for bioaccumulation experiments in medium- to large-sized monitoring programs. The authors observed a good correlation of $\mathrm{Hg}$ concentrations in Chironomus riparius versus indigenous chironomids, suggesting the possibility of using linear regressions to predict $\mathrm{Hg}$ accumulation by these benthic invertebrates [1].

The review of $\mathrm{Hg}$ uptake in the freshwater macrophyte Elodea nuttallii, authored by Cosio (2020), demonstrates that this plant bioaccumulates both $\mathrm{IHg}$ and $\mathrm{MMHg}$ [3]. Nonetheless, IHg shows a higher affinity to cell walls and a basipetal in planta transport, whereas MMHg acropetal transport was evidenced [3]. In contrast, uptake in the absence of dissolved organis matter (DOM) in water gave highly similar enrichment factor for $\mathrm{IHg}$ and $\mathrm{MMHg}$, resulting in similar intracellular $\mathrm{THg}$ concentration in E. nuttallii, pointing to a role of affinity to DOM in the observed difference between the fate of IHg and MMHg observed in biota in the field [3]. 
In the same line, the paper authored by Monperus et al. (2020) evidenced a contrasted toxicokinetic of IHg and MMHg in glass eels [2]. After rapid uptake through the gills, MMHg was transported in the heart, the liver, and the brain, and finally transferred to the skeletal muscles. IHg uptake was also mainly observed in gills but transited through olfactory bulbs with a very low transfer and storage in the other organs and a rapid depuration [2]. As previously observed in E. nuttallii, data supported the importance of chemical speciation on the target cells and tissues for $\mathrm{Hg}$ accumulation [2].

\section{Food Web Transfer to Fish}

Two papers addressed food web transfer of $\mathrm{Hg}$ to fish [4,5]. The paper, authored by Gentès et al. (2020), determined the bioavailability of MMHg in aquatic freshwater system, revealing MMHg production in plant roots and MMHg trophic transfer to Pseudancistrus sp. tissues and gut [4]. Authors highlight that MMHg formed in the periphyton could significantly participate in food web contamination, because aquatic plants are an important food source [4]. The paper, authored by Camacho et al. (2020), assessed the bioaccumulation of $\mathrm{Hg}$ in the commercial marine flat fish species Solea senegalensis co-exposed to dietary MMHg and climate change (warming and acidification) [5]. Fish liver exhibited the highest $\mathrm{Hg}$ concentration, followed by brain and muscle [5]. Warming enhanced $\mathrm{Hg}$ bioaccumulation, whereas acidification decreased this element's levels [5]. Hazard quotient (HQ) estimations evidenced that human exposure to $\mathrm{Hg}$ through the consumption of fish species may be aggravated in tomorrow's oceans, thus raising concerns for future seafood safety [5].

\section{Effect of $\mathrm{Hg}$ in Biota}

Two papers detailed effects of $\mathrm{Hg}$ in biota [3,5]. In the macrophyte E. nuttallii, IHg reduced chlorophyll, while MMHg increased anthocyanin [3]. Transcriptomics and metabolomics in shoots revealed that $\mathrm{MMHg}$ regulated a higher number of genes and metabolites than $\mathrm{IHg}$ [3]. Proteomics and metabolomics in cytosol revealed that IHg had a greater effect than $\mathrm{MMHg}$ [3]. In sum, MMHg and IHg showed different cellular toxicity pathways [3]. The main impact of MMHg and IHg was on the non-soluble compartment and the soluble compartment, respectively [3]. This is congruent with the higher affinity of IHg with DOM and cell walls.

In S. senegalensis. neuro-oxidative responses were affected by both climate change-related stressors and $\mathrm{Hg}$ dietary exposure [5]. Exposure to dietary $\mathrm{MMHg}$ reduced weight, length, catalase (CAT) and superoxide dismutase (SOD) activities in muscles and the liver, respectively, and increased catalase and acetylcholinesterase activities in the brain, as well as the lipid peroxidation (LPO) in the brain [5]. Interactions with warming and acidification were antagonistic for growth, CAT in the liver and the brain, SOD in the muscle and the liver, and LPO in the brain [5]. Authors suggested for these interactions to take place via variations of metabolic rates [5]. The three studied stressors elicited differential neuro-oxidative responses in fish muscle, liver, and brain [5]. Such differences can be mostly attributed to the different $\mathrm{Hg}$ concentrations accumulated in tissues (liver $>$ brain $>$ muscle), and to specific modes of action in target organs [5]. As such, data showed a more notorious neuro-oxidative response in the brain [5]. The data support the viewpoint that seafood safety will be likely compromised if the climate continues to change as projected. The authors stress that future legislation and recommendations regarding $\mathrm{Hg}$ risk assessment should account for the expected effects of warming, while advising a conscious and parsimonious consumption of wild seafood species [5].

\section{Effect of Dietary Hg to Microbiota}

In the past decade, the intestinal microbiota has been recognized as a major player in the health of its host as it takes part in major biological functions, including nutrition, immunity, and the metabolism of xenobiotics. As such, it is hypothesized to play a major role in the exposure of the host to dietary pollutants, including $\mathrm{Hg}$. Two papers studied the impact of $\mathrm{Hg}$ on microbiota $[4,6]$. The paper authored by Brantschen et al. revealed changes in microbiota of earthworms exposed to $\mathrm{Hg}$ contaminated soils [6]. Data pointed out that the health of macro-organisms in the food web might be impacted 
through changes in their gut microbiome, subsequently affecting their metabolism and legacy in the soil [6].

In fish exposed to roots of macrophytes, methylating bacteria were identified in the gut contents of the fish [4]. As such, authors observed not only the dietary transfer of $\mathrm{MMHg}$, but also of bacteria from plants to fish [4]. Besides, $\mathrm{Hg}$ methylation is strongly suspected in the fish gut, potentially increasing the $\mathrm{Hg}$ bioaccumulation. This endogenous methylation is a current major question in the context of the environmental impact of $\mathrm{Hg}$ and the understanding of the $\mathrm{Hg}$ cycling in ecosystems [4].

\section{Development of New Approaches}

Two papers that presented recent methodological progress are promising for the understanding of the bioaccumulation and effect of $\mathrm{Hg}[2,3]$. A multi-isotope image mapping procedure was developed by Monperrus et al. (2020) to simultaneously study the uptake and distribution of both MMHg and IHg within the organs of glass eels [2]. Cosio (2020) coupled multiomics approaches to identify cellular toxicity pathways at several levels of organization and the early impact of sublethal pollution [3].

In 2013, the nations of the world agreed on the first global treaty to mitigate the many deleterious health outcomes associated with $\mathrm{Hg}$ release into the environment and $\mathrm{MMHg}$ exposure. In this context, all the papers in this Special Issue provide innovative insights into the $\mathrm{Hg}$ fate in the aquatic and terrestrial ecosystems and increase the understanding of the $\mathrm{Hg}$ biogeochemical cycle [1-6].

Funding: This research received no external funding.

Acknowledgments: Thanks are due to all the authors and peer reviewers for their contributions to this Special Issue and to the editorial team of Applied Sciences.

\section{References}

1. Vignati, D.A.; Bettinetti, R.; Boggero, A.; Valsecchi, S. Testing the use of standardized laboratory tests to infer $\mathrm{Hg}$ bioaccumulation in indigenous benthic organisms of Lake Maggiore (NW Italy). Appl. Sci. 2020, $10,1970$. [CrossRef]

2. Monperrus, M.; Pécheyran, C.; Bolliet, V. Imaging differential mercury species bioaccumulation in glass eels using isotopic tracers and laser ablation inductively coupled plasma mass spectrometry. Appl. Sci. 2020, 10, 2463. [CrossRef]

3. Cosio, C. Inorganic mercury and methyl-mercury uptake and effects in the aquatic plant Elodea nuttallii: A review of multi-omic data in the field and in controlled conditions. Appl. Sci. 2020, 10, 1817. [CrossRef]

4. Gentès, S.; Monperrus, M.; Legeay, A.; Gassie, C.; Maury-Brachet, R.; André, J.-M.; Guyoneaud, R. Influence of macrophyte and gut microbiota on mercury contamination in fish: A microcosms study. Appl. Sci. 2020, 10, 1500. [CrossRef]

5. Camacho, C.; Maulvault, A.L.; Santos, M.T.; Barbosa, V.; Fogaça, F.H.S.; Pousão-Ferreira, P.; Nunes, M.L.; Rosa, R.; Marques, A. Mercury in juvenile Solea senegalensis: Linking bioaccumulation, seafood safety, and neuro-oxidative responses under climate change-related stressors. Appl. Sci. 2020, 10, 1993. [CrossRef]

6. Brantschen, J.; Gygax, S.; Mestrot, A.; Frossard, A. Soil Hg contamination impact on earthworms' gut microbiome. Appl. Sci. 2020, 10, 2565. [CrossRef] 